\title{
Chest CT imaging of an early Canadian case of COVID-19 in a 28-year-old man
}

\author{
Navneet Singh MD PhD, Jennifer Fratesi MD
}

Cite as: CMAJ 2020 April 27;192:E455. doi: 10.1503/cmaj.200431; early-released April 15, 2020

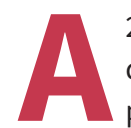

28-year-old man with asthma presented to the emergency department on Mar. 16, 2020, with chest discomfort, nonproductive cough and dyspnea despite use of a salbutamol inhaler. He had no travel or contact history. He reported 3 to 5 days of antecedent fevers, myalgias and arthralgias, and use of acetaminophen. Physical examination showed normal basilar breath sounds and scattered wheezes. His vital signs were stable $\left(36.8^{\circ} \mathrm{C}\right.$, peripheral oxygen saturation $\left[\mathrm{SpO}_{2}\right] 100 \%, 85$ beats/min and blood pressure $130 / 79 \mathrm{~mm} \mathrm{Hg}$ ). His bloodwork was normal except for his C-reactive protein $(32$ [normal $<11$ ] $\mathrm{mg} / \mathrm{L})$ and lymphocytes (0.4 [normal $1.5-4] \times 10^{3}$ cells $\left./ \mu \mathrm{L}\right)$.

A computed tomography (CT) scan of the patient's chest (Figure 1) showed the typical appearance of COVID-19 pneumonia, according to a recent Radiology Society of North America expert consensus statement on chest CT findings of coronavirus disease 19 (COVID-19), including bilateral peripheral and rounded ground-glass opacities and regions of peripheral consolidation. ${ }^{1}$ The radiologic differential included bilateral pneumonia caused by typical or atypical pathogens, drug toxicity and organizing pneumonia.

A subsequent nasopharyngeal swab, taken in the emergency department immediately after the CT scan, was positive for COVID19 by reverse transcription polymerase chain reaction (RT-PCR; Seegene Allplex 2019-nCoV Assay), detecting RNA-dependent RNA polymerase (RdRp), envelope and nucleocapsid genes. The patient was admitted to a general medical ward, received oseltamivir and made a full recovery without admission to an intensive care unit.

Routine screening or diagnosis with CT scanning for COVID-19 is not recommended owing to cost, resource constraints during a pandemic and risk of spreading infection. ${ }^{2}$ However, CT may be used to expedite care in symptomatic patients with a negative or pending swab, and in those with worsening respiratory status or developing complications such as empyema or acute respiratory distress syndrome. One recent study of 601 patients showed chest CT scanning to be $97 \%$ sensitive, but only $25 \%$ specific compared with RT-PCR testing, ${ }^{3}$ which is both sensitive and specific (95\%-97\%). ${ }^{4}$ Our Canadian case highlights CT imaging features of COVID-19 consistent with the international experience. ${ }^{5}$

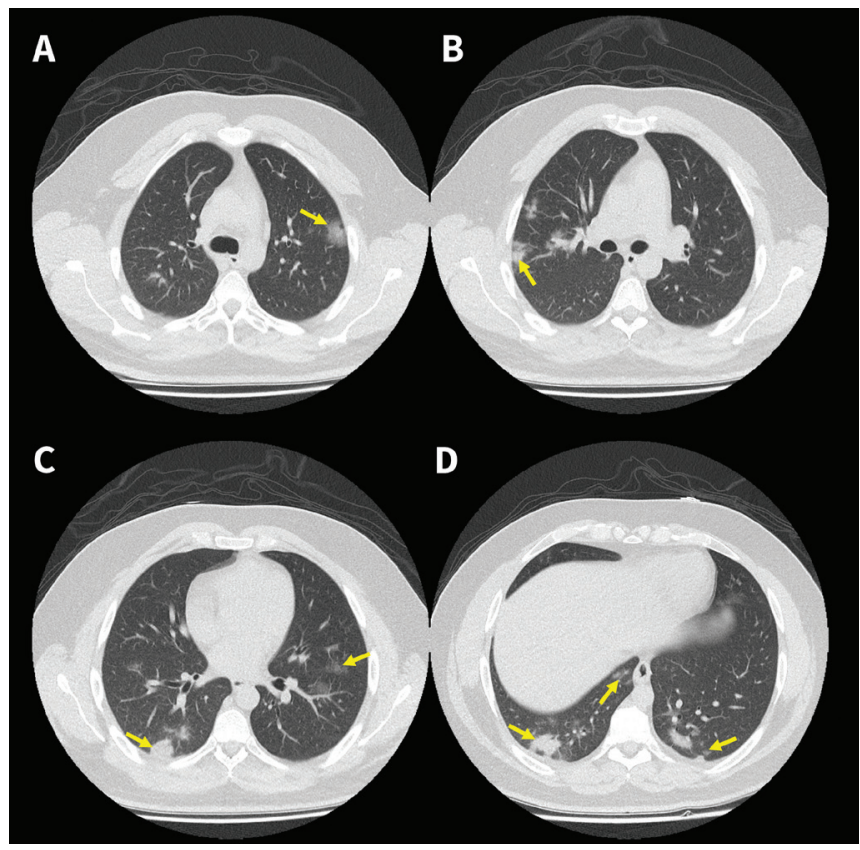

Figure 1: Chest computed tomography scan of a 28-year-old man, showing multifocal bilateral peripheral rounded and ill-defined ground-glass opacities ( $A$ and $B$ ) with regions of rounded consolidation in the lower lobes ( $C$ and $D)$.

\section{References}

1. Simpson S, Kay FU, Abbara S, et al. Chest CT findings related to COVID-19. Endorsed by the Society of Thoracic Radiology, the American College of Radiology, and RSNA. Radiology: Cardiothoracic Imaging 2020 Mar. 25. doi.org/10.1148/ryct.2020200152.

2. ACR Recommendations for the use of chest radiography and computed tomography (CT) for suspected COVID-19 infection. Reston (VA): American College of Radiology; updated 2020 Mar. 22. Available: www.acr.org/Advocacy-and -Economics/ACR-Position-Statements/Recommendations-for-Chest-Radiography -and-CT-for-Suspected-COVID19-Infection (accessed 2020 Mar. 17).

3. Ai T, Yang Z, Hou H, et al. Correlation of chest CT and RT-PCR testing in Coronavirus disease 2019 (COVID-19) in China: a report of 1014 cases. Radiology 2020 Feb. 26:200642. doi: 10.1148/radiol.2020200642.

4. Mossa-Basha M, Meltzer CC, Kim DC, et al. Radiology department preparedness for COVID-19: Radiology Scientific Expert Panel. Radiology 2020 Mar. 16:200988. doi: 10.1148/radiol.2020200988.

5. Shi H, Han X, Jiang N, et al. Radiological findings from 81 patients with COVID19 pneumonia in Wuhan, China: a descriptive study. Lancet Infect Dis 2020 Feb. 24. doi.org/10.1016/ S1473-3099(20)30086-4.

\section{Competing interests: None declared.}

This article has been peer reviewed.

The authors have obtained patient consent.
Affiliations: Department of Medical Imaging, Faculty of Medicine, University of Toronto; Toronto General Hospital, Joint Department of Medical Imaging-University Health Network, Toronto, Ont.

Correspondence to: Navneet Singh, navneet.singh@utoronto.ca 